\title{
Influența teologiei occidentale asupra lui N. Steinhardt în abordarea impasibilității lui Hristos
}

Florin Toader TOMOIOAGĂ*

Abstract: The Influence of Western Theology on N. Steinhardt in Approaching Christ's Impassibility. In the work of the famous Romanian writer of Jewish origin, Nicolae Steinhardt, Christ's impassibility may be approached from two points of view. The first one is a scholarly perspective, tracing the historical and doctrinal roots of his thinking. The second one is a spiritual perspective, projecting the image of the suffering Christ as a helper of those experiencing sufferance, of the vulnerable ones. The study combines both perspectives, underlining the interplay between Christ's impassibility and His capacity of suffering. Its starting point represents my hypothesis that N. Steinhardt's originality on this topic is dependent upon the Western sources of his thinking. At the end of this article it will become evident that theologians like Dietrich Bonhoeffer, Hans Urs von Balthasar and Rudolf Bultmann had a tremendous influence on Steinhardt's thinking. Besides this demonstration from the point of view of the history of ideas/dogmas, the article stresses the spiritual contribution of Steinhardt's view at time of challenge, like the contemporary pandemic global crisis.

Keywords: N. Steinhardt, Hans Urs von Balthasar, divine impassibility, Cross, compassion.

* Diacon, Lector Universitar Doctor, Facultatea de Teologie Ortodoxă „Episcop Dr. Vasile Coman”, Universitatea din Oradea, România. 


\section{Introducere: actualitatea gândirii lui N. Steinhardt în context pandemic}

La începutul anilor '90, lumea culturală și teologică din România era luată prin surprindere de publicarea unui adevărat jurnal de rezistență spirituală - Jurnalul fericirii, semnat de Părintele Nicolae Steinhardt. Este mărturia unui spirit care a cunoscut prefacerile credinței într-un context de criză personală cel al arestării și încarcerării scriitorului de origine iudaică, și socială - de impunere cu brutalitate a utopiei comuniste. Soluțiile spirituale $^{1}$ avansate de N. Steinhardt, reflectând înțelepciunea creștină, au o dimensiune universală. Prin urmare, acestea sunt valabile în orice context de criză, pentru că au în centrul lor imaginea lui Hristos pătimitor - a lui Dumnezeu întrupat care poate să fie alături de cei ce suferă fiindcă și El a traversat Valea Plângerii, a asumat durerea omenească, dar a și transfigurat-o, i-a schimbat semnificația din pregustare a morții în participare la Cruce şi, deci, la Înviere.

Studiul de față se axează pe creionarea reperelor spirituale propuse de Părintele Nicolae Steinhardt ca soluții pentru atmosfera socială actuală. Această atmosferă este marcată de criza sanitară și umană generată de răspândirea COVID-19. Pandemia a produs schimbări sociale și economice majore, afectând viețile a milioane de oameni. Factorul psihic al fenomenului - poate cel mai neglijat de către autoritățile publice și politice - nu poate fi abordat decât din perspectiva credinței, a spiritualității. Iar aici, gândirea lui N. Steinhardt își demonstrează încă o dată actualitatea și fecunditatea prin accentul pe care îl pune asupra temei suferinței lui Iisus.

Lucrarea va surprinde modul original în care autorul îmbină tratarea tradiţională a temei - în linie scripturistică, cu o tratare

${ }^{1}$ Vezi, de asemenea, o interpretare a soluțiilor propuse de N. Steinhardt pentru protejarea libertății personale, spirituale la Florin Toader ToMOIOAGĂ, „Despre autoritate și libertate în sistem”, în rev. Convergențe (https://convergente.ro/despre-autoritate-si-libertate-in-sistem/). 
modernă - în acord cu gândirea teologică occidentală contemporană lui. Teza principală a studiului este aceea că autorul român a fost puternic influențat de gândirea apuseană în tratarea impasibilității divine a lui Hristos. Astfel, primul subpunct expune interpretarea pe care monahul de la Rohia o dă strigătului de pe Cruce al Mântuitorului. Cel de al doilea subpunct prezintă realismul suferinței și vulnerabilității lui Hristos ca dovadă a Întrupării și corolar obligatoriu al acesteia, iar ultimul subpunct dezvoltă raportul dintre impasibilitatea divină și capacitatea lui Hristos de a suferi.

\section{Eloi, Eloi, lama sabahtani? (Marcu 15, 34) - în interpretarea lui N. Steinhardt}

Lumea teologică occidentală s-a scindat, situându-se pe poziții diametral opuse în ceea ce privește interpretarea versetului 34 din Marcu 15: Eloi, Eloi, lama sabahtani? Să fie vorba despre o citare a Psalmului 21, 1 („Dumnezeul meu, Dumnezeul meu, ia aminte la mine, pentru ce m-ai părăsit?") sau despre un strigăt spontan al Mântuitorului? În timp ce teologi precum Hans Urs von Balthasar susțin spontaneitatea acestui strigăt ${ }^{2}$, alții, precum Joseph Ratzinger-Benedict al XVI-lea ${ }^{3}$ și Brant Pitre ${ }^{4}$, pe fundamente mai puțin speculative și mai coerente teologic, afirmă corelația dintre cele două versete și, deci, o referire intenționată a Mântuitorului la Psalmul 21 în cea mai atroce clipă a Pătimirilor Sale.

Desigur că această ultimă perspectivă pare a implica o afirmare mai puternică a impasibilității Mântuitorului. S-ar putea argumenta că, dacă pe Cruce Hristos citează psalmi, înseamnă că nu suferă cu adevărat, că este impasibil. Impasibilitatea divină

${ }^{2}$ Hans Urs vOn BAlthasaR, Mysterium Paschale. The Mystery of Easter, trad. și introducere Aidan Nichols, San Francisco, Edit. Ignatius Press, 2005, p. 96.

${ }^{3}$ Joseph RATZINGER, Isus din Nazaret. Partea a II-a. De la intrarea în Ierusalim la Inviere, trad. Cristian Langa, Cristina Palici și Mihai Pătraşcu, Târgu-Lăpuş, Edit. Galaxia Gutenberg, 2012, p. 203.

${ }^{4}$ Brant Pitre, Fiul lui Dumnezeu? Pledoarie pentru Isus, trad. Tatiana Niculescu, București, Edit. Humanitas, 2017, p. 191. 
pare a contrazice, în acest context, deplina umanitate a lui Hristos, care trebuie să se manifeste, în mod natural, conform trăsăturilor specifice acesteia: resimțirea durerii, a singurătății, a tulburării în fața morții.

Unei astfel de necesități teologice răspunde Părintele N. Steinhardt, cu eseurile sale dedicate obsedantei teme a strigătului lui Hristos. Tema apare frecvent în paginile din Jurnalul fericirii și este reluată în Dăruind vei dobândi. Acest fapt nu ar trebui să mire pe nimeni. Reflecțiile Jurnalului fericirii au loc într-un univers dominat de tortură, în iadul temnițelor comuniste în care strigătul părăsirii este o experiență reală și terifiantă. Dacă în celebrul tablou al lui Salvador Dali, Hristos al Sfântului Ioan al Crucii, perspectiva amețitoare asupra Crucii este dinspre cer spre pământ ${ }^{5}$, la N. Steinhardt aceasta este complet inversată. El privește Crucea dinspre Hades, din abisul infernului spre cer.

Într-o asemenea viziune, Hristos este cu adevărat uman doar dacă nu Se comportă cu seninătate imperială, cu tărie sufletească neverosimilă, în contexte în care orice om obişnuit cedează, devine vulnerabil. $\mathrm{Cu}$ alte cuvinte doar dacă, atunci când este confruntat cu perspectiva morții, Mântuitorul Se înfioară și Se tulbură, asemenea oricărui om. Pentru N. Steinhardt, acesta este testul suprem al umanității Sale. Și recurge la o întreagă pleiadă de argumente, de la cele de tip literar până la cele luate din artele plastice, pentru a susține realitatea suferinței și, deci, a umanității lui Hristos.

Pentru scriitor, strigătul Eloi, Eloi, lama sabahtani? are rolul de a pune în evidență caracterul real al firii umane a lui Hristos, contestat vehement de ereziile de factură gnostică, cu fond dochetist. „Numai strigătul Eli, Eli ne dovedește că răstignitul nu sa jucat cu noi, că nu a încercat să ne mângâie cu făţarnice estompări’", notează acesta. Hristos suferă în mod real, deci devine

${ }^{5}$ De altfel, într-un dialog cu Ioan Pintea, Părintele Steinhardt explică acest tablou și de ce îl consideră pe Salvador Dali „un mare artist creștin”, cu o ,,pictură metafizică" în Ioan PINTEA, Insoțiri în Turnul Babel, Craiova, Edit. Omniscop, 1996, p. 45.

${ }^{6}$ Nicolae StEInHARDT, Jurnalul fericirii, Cluj-Napoca, Edit. Dacia, 1995, p. 55. 
slab pentru noi - și doar astfel poate fi solidar cu cei ce, asemenea Lui, sunt slabi și suferă fără vină. Parafrazându-l pe germanul Dietrich Bonhoeffer, Părintele Steinhardt afirmă: „Hristos ne vine în ajutor mai ales întrucât e slab, adică întrucât e pe cruce, deci lipsit de putere, întrucât e jertfă de bunăvoie pentru iertarea păcatelor noastre. Hristos cel slab este de fapt Hristos cel puternic. El ne mântuiește prin voita lui slăbiciune"7 .

Aceste cuvinte redau liber un fragment din opera epistolară a teologului german. „Dumnezeu Se lasă împins în afara lumii pe Cruce. El este slab și lipsit de putere în lume, și tocmai aceasta este calea, singura cale, prin care El este cu noi și ne ajută. Matei 8, 17 arată clar faptul că Hristos ne ajută, nu în virtutea atotputerniciei Sale, ci în virtutea slăbiciunii și suferinței Sale... Doar un Dumnezeu care suferă poate ajuta... Aceasta este o răsturnare a ceea ce omul religios așteaptă de la Dumnezeu. Omul este chemat să ia parte la suferințele lui Dumnezeu produse de o lume fără Dumnezeu", scrisese Dietrich Bonhoeffer în închisoare în anul $1944^{8}$. De fapt, cuvintele sale - ,fericirea noastră este ascunsă în suferință şi viaţa noastră în moarte" " - pot constitui motto-ul inspirator și rezumativ al titlului cărții Jurnalul fericirii.

\section{Suferința și vulnerabilitatea lui Hristos ca dovadă a Întrupării}

Conform dochetismului, umanitatea hristică este doar o fantoșă ,,purtată” ca veșmânt exterior, aparent, de o ființă spirituală coborâtă din „,cer” - Hristos. În vecinătate de idei se situează monofizitismul, după care umanitatea lui Hristos este absorbită treptat de divinitatea $\mathrm{Sa}$, și ceea ce mai rămâne în final este o

${ }^{7}$ Ioan PINTEA, op. cit., p. 46.

${ }^{8}$ Dietrich BonhoefFer, Letters and Papers from Prison, The Enlarged Edition, SCM Press, 1971, p. 360 ș. urm., apud Jürgen MolTMAnN, The Crucified God: the Cross of Christ as the Foundation and Criticism of Christian Theology, trad. R. A. Wilson și John Bowden, Minneapolis, Edit. Fortress Press, 1993, p. 47.

${ }^{9}$ Dietrich BonhoefFer, op. cit., p. 391, apud Jürgen Moltmann, op. cit., p. 146. 
singură fire, cea divină, desigur. Monofizitismul este doar o versiune, mai subtilă, a dochetismului ${ }^{10}$.

Ambele erezii primesc o puternică replică în scrierile lui N. Steinhardt, fiindcă ambele minimalizează suferința Mântuitorului, în fond însăși umanitatea Sa, însuși faptul Întrupării Fiului lui Dumnezeu și, prin aceasta, capacitatea Sa de a fi co-pătimitor cu cei ce suferă. De fapt, miza este realismul și realitatea mântuirii. În propriile sale cuvinte, Steinhardt afirmă:

„Hristos nu s-a urcat întâmplător pe cruce: curajul îndurării unor suferinţ̧e cumplite a fost singura cale prin care a putut arăta că s-a făcut om cu adevărat, în întregime; prin care şi-a putut dovedi buna-credinţă" ${ }^{\prime 1}$.

Dar, la rândul ei, realitatea suferinței Mântuitorului este subliniată tocmai de deznădejdea - în plan uman - pe care strigătul Său pare a o manifesta. Realismul Crucii condiționează însăși convertirea gânditorului evreu la creștinism, după cum mărturisește, pentru că stă în strânsă legătură cu ideea de jertfă:

„Răstignirea nu e farsă și înșelăciune decât dacă se constată că orice miracol este cu neputinţă, orice înviere este un basm. Dacă monofiziţii, dochetiştii ori fantaziaştii ar avea dreptate, în ruptul capului n-aş fi trecut la creştinism. Ar însemna că răstignirea a fost în cel mai bun caz un simbol ori o reprezentaţie. Să nu fie! Numai deznădejdea omenească de pe cruce dovedeşte integritatea şi seriozitatea jertfei, o împiedică a fi cine ştie ce joc, ce vicleim"12.

\section{Raportul dintre impasibilitatea divină şi capacitatea lui Hristos de a suferi}

Dacă monofizismul și dochetismul susțin, în esență, perfecta impasibilitate a lui Hristos, Părintele Steinhardt merge în sens invers, negând total impasibilitatea lui Hristos pe Cruce: „Dacă şi-ar fi

${ }^{10}$ Vezi termenul „Monophysitism” în Jean-Yves LACOSTE (ed.), Encyclopedia of Christiam Theology, vol. 2, New York, Londra, Edit. Routledge, 2005, p. 1060-1061.

${ }^{11}$ Nicolae STEINHARDT, Jurnalul fericirii, p. 186.

12 Ibidem, p. 55. 
păstrat - măcar în parte - impasibilitatea pe cruce, dacă n-ar fi gustat din plin deznădejdea omului, evenimentul petrecut pe Golgota n-ar fi fost - pentru filosofi, pentru preoţi şi pentru prostime - prilej de poticnire şi sminteală, ci «scenariu» ori «ritual», deci admisibil, comestibil"13. Deci Mântuitorul nu Își păstrează impasibilitatea, tocmai pentru a nu da naștere unei credințe lipsite de provocări, superficială, ușor de admis de toată lumea.

Să fie vorba aici despre ocultarea intenționată a acestui atribut fundamental al lui Hristos - impasibilitatea firii Sale divine - sau despre o scăpare teologică? Această ultimă ipoteză este greu de acceptat în cazul unui autor care înțelegea toate subtilităţile gândirii dogmatice. Dar, ca eseist, utilizând un stil lapidar, aforistic și anecdotic, nu operează cu distincții dogmatice prea exacte. În plus, N. Steinhardt împinge până la ultimele limite gândirea ortodoxă prin limbajul său peremptoriu.

Dovadă în acest sens sunt expresiile următoare - de altfel, cu substrat biblic și patristic: „Dumnezeu răstignit”, „divinitatea nu numai așezată pe cruce - solemniter -, ci pironită cu adevărat" 14 . Contextul în care apar pasajele de mai sus indică în direcția negării impasibilității firii divine a lui Hristos - nu însă din pura plăcere ludică de a şoca, ci având ca miză afirmarea compasiunii Domnului. Cuvintele lui Dietrich Bonhoeffer, „Doar un Dumnezeu care suferă poate ajuta"15, par a rezuma întreaga filozofie steinhardtiană pe acest subiect.

Părintele N. Steinhardt insistă asupra pasajelor din Epistola către Evrei ${ }^{16}$ pentru a sublinia compasiunea lui Hristos cu cei ce suferă tocmai datorită faptului că a traversat El însuşi Valea Plângerii. Astfel, Steinhardt trimite la Evrei 2, 17-18, unde Sf. Ap. Pavel scrie: „Pentru aceea, dator era întru toate să Se asemene fraţilor, ca să fie milostiv şi credincios arhiereu în cele către Dumnezeu, pentru curăţirea păcatelor poporului. Căci prin

\footnotetext{
13 Ibidem, p. 56.

${ }^{14}$ Ibidem, p. 56.

15 Dietrich BonHOEFFER, op. cit., p. 360 ș. urm., apud Jürgen Moltmann, op. cit., p. 47.

${ }^{16}$ Nicolae SteInHaRdT, Jurnalul fericirii, p. 57.
} 
ceea ce a pătimit, fïind El însuşi ispitit, poate şi celor ce se ispitesc să le ajute". De asemenea, apare menționat și Evrei 4, 15: „Că nu avem Arhiereu care să nu poată suferi cu noi în slăbiciunile noastre, ci ispitit întru toate după asemănarea noastră, afară de păcat".

Compasiunea lui Hristos e atât de puternică încât, chiar întrun context dramatic precum cel al penitenciarelor politice, autorul afirmă: ,... încep să presimt că Hristos e prezent în puşcărie. Nu-mi vine să cred că totul poate fi atât de complet, că am parte de atâta binecuvântat noroc"17.

Indiferent de sensul precis pe care Steinhardt 1-a conferit impasibilității Mântuitorului, aceasta nu poate fi negată din punct de vedere teologic. Hristos devine vulnerabil, în suferință, nu pentru a rămâne la nivelul celor neputincioși, ci pentru a-i înălţa pe oameni din această stare. Dar aceasta presupune impasibilitatea $\mathrm{Sa}$ ca Dumnezeu, puterea Sa nediminuată ca temei al ajutorării celor slabi. După cum arată Paul Gavrilyuk în amplul său studiu dedicat relației dintre pasibilitatea și impasibilitatea divină, cele două sunt concepte corelative, de care nu se poate face abstracție în creionarea iconomiei mântuiriii ${ }^{18}$.

Este evident că Părintele Steinhardt intuiește în conceptul de impasibilitate un potențial pericol. Și acesta constă în înțelegerea termenului prin prisma metafizicii lui Platon și Aristotel, pentru care nepătimirea $(\alpha \pi \alpha ́ \theta \varepsilon 1 \alpha)$ echivalează cu nepăsarea, indiferenţa, incapacitatea de a fi afectat de influențele externe, neschimbabilitatea ${ }^{19}$. Un astfel de Dumnezeu, impasibil, adică „apatic”, Steinhardt nu își putea imagina.

În plan teologic, imaginea divinului pe care o creionează contrazice imaginea filozofică a divinității reci, detaşate, inaccesibile și maiestuoase. $\mathrm{O}$ astfel de divinitate nu se putea nici întrupa, nici răstigni, pare a spune monahul de la Rohia. Într-o meditație jucăușă și originală ce amintește de doctrina sefirotică a

${ }^{17}$ Ibidem, p. 59.

18 Paul L. Gavrilyuk, Pătimirea Dumnezeului nepătimitor. Dialecticile gândirii patristice, trad. Dragoș Dâscă, Iași, Edit. Doxologia, 2013, p. 42.

${ }^{19}$ Vezi Jürgen MoltmanN, op. cit., p. 267-268. 
Cabalei $^{20}$, Steinhardt propune o imagine caldă a lui Dumnezeu, care depășește toate reprezentările reci ale sistemelor filozofice sau teosofice. După ce „străbate” noetic cele opt „ceruri” inferioare, lăsând în urmă galaxiile și eonii, autorul Jurnalului fericirii ajunge la ,adevăratul” Dumnezeu: „divinitatea din cerul al nouălea nu este o «forţă» sau o «energie», cât mai impasibilă şi mai impersonală, un ascuns coordonator sau constructor, ci este Dumnezeu cel cu barbă albă, blând şi bun. Dumnezeul copilăriei celei mai îndepărtate şi al colindelor, al cozonacilor, colindeţelor şi turtelor, al celor mai frumoase seri de Crăciun..." ${ }^{21}$. Și, în continuare: „Dumnezeul cel mai de sus, final, din taina tainelor şi sfânta sfintelor nu este câtuși de puţin cel abstract, nu e Creatorul rece, nu e Brahma necuprins şi neschimbabil, nu e cugetătoarea zeitate a gnosei, depănând eonii" 22 . În ceea ce privește Dumnezeul creștin concret, Sfânta Treime, autorul pare a sublinia aceeași disponibilitate participativă la bucuria și tristețea umană. „Ideea Treimii”" este cea mai înaltă în context filozofic și religios, fiindcă face trecerea de la divinitatea creatoare la divinitatea jertfitoare, „,iubitoare de oameni până la jertfă, izbăvitoare și consolatoare"23.

Cadrul dogmatic în care își inserează observațiile este dat de susținerea unei alternanțe în manifestarea celor două naturi ale lui Hristos. Altfel spus, evenimentele vieții Fiului divin întrupat reliefează când firea $\mathrm{Sa}$ divină, când cea umană, în funcție de context, fără a fi împiedicată comunicarea însușirilor. După cum notează monahul de la Rohia, ,pe cruce, în ciuda comunicării idioamelor, în ciuda faptului că [Iisus] avea deplina conștiință a învierii, natura omenească pare a fi covârşită oarecare timp - după cum, contrapunctic, a predominat natura divină pe muntele Tabor -,

20 „Cabaliștii afirmau că există niveluri la care Divinitatea se revelează în funcție de o anumită stare corespunzătoare unui eon determinat, și anume o vârstă a lumii”, vezi Maurice-Ruben HAYOUN, „Iudaismul”, în Jean DELUMEAU (coord.), Religiile lumii, trad. Carol Litman, București, Edit. Humanitas, 2014, p. 220.

${ }^{21}$ Nicolae STEINHARDT, Jurnalul fericirii, p. 162.

${ }^{22}$ Ibidem, p. 162.

${ }^{23}$ Ibidem, p. 163. 
căci altfel nu s-ar fi auzit atât de firescul mi-e sete și nici atât de allzumenschlich-ul: Dumnezeul meu, de ce m-ai părăsit?"24.

Acesta vorbește despre o manifestare copleșitoare a uneia dintre firi, în anumite momente, fără afectarea comunicării însușirilor, adică fără ca una să fie trăită de Hristos separat de cealaltă. Dacă așa ceva ar fi posibil, Mântuitorul „S-ar manifesta când ca pur dumnezeiesc, când ca pur omenesc"25, conform Părintelui Stăniloae. Principiul comunicării însuşirilor nu este anulat la Părintele Steinhardt; acest fapt presupune unirea firilor şi integritatea lor în Întrupare, în sensul definiției dogmatice a Sinodului IV ecumenic de la Calcedon (451).

Părintele Steinhardt, de altfel, face trimitere la sinodul de la „Halchidon”. Se poate presupune, prin urmare, că acesta consideră formula diofizită a sinodului ca fiind obligatorie pentru orice interpretare hristologică validă. Definiția de credință respectivă afirmă că Mântuitorul Hristos trebuie ,,cunoscut în două firi în chip neamestecat și neschimbat, neîmpărțit și nedespărțit, deosebirea firilor nefiind nicidecum distrusă prin unire, păstrându-se mai ales însuşirea fiecăreia şi întâlnindu-se împreună într-o singură persoană..."26. Dar definiția presupune păstrarea impasibilității divine chiar și în suferința Crucii, fiindcă nepătimirea este o însuşire/trăsătură a firii dumnezeiești.

Dacă impasibilitatea este negată în paginile eseistice menționate, aceasta se întâmplă probabil datorită lecturilor din teologia apuseană, cu care Părintele Steinhardt este familiarizat, și a utilizării unui limbaj peremptoriu. Așa cum s-a observat, N. Steinhardt citește scrierile lui Dietrich Bonhoeffer pe care îl citează și în Jurnalul fericirii. De asemenea, cunoaște operele lui Karl Barth, Paul Tillich, Rudolf Bultmann ${ }^{27}$ și Hans Urs von Balthasar ${ }^{28}$. Ideea

\footnotetext{
${ }^{24}$ Ibidem, p. 55.

${ }^{25}$ Dumitru Stăniloae, Teologia dogmatică ortodoxă, vol. II, ediția a doua, București, Edit. Institutului Biblic şi de Misiune al Bisericii Ortodoxe Române, 1997, p. 40.

26 Nicolae CHIFĂR, Istoria creștinismului I, Sibiu, Edit. Universităţii „Lucian Blaga”, 2007, p. 191-192.

${ }^{27}$ Cei trei sunt citați împreună în Jurnalul fericirii, p. 372.
} 
vulnerabilității lui Hristos pe Cruce este împinsă la extrem de Rudolf Bultmann, teolog pe care monahul de la Rohia îl menţionează frecvent în opera sa ${ }^{29}$. Asumând uneori gândirea teologică apuseană sau polemizând alteori cu ea, N. Steinhardt reușește să o „traducă” în limbajul culturii autohtone, într-o vreme când, după anii instalării comunismului în Răsăritul Europei, România era aproape total izolată de cultura occidentală și de prefacerile prin care trecea.

\section{Concluzii}

Tema impasibilităţii lui Hristos poate fi abordată la N. Steinhardt cel puțin din două unghiuri: unul este cel al teologiei dogmatice, mai precis al istoriei dogmelor, celălalt este cel spiritual. Studiul de față a urmărit abordarea ambelor aspecte, care sunt complementare. Se impun câteva concluzii din ambele perspective.

În a doua jumătate a secolului al XX-lea, teologi fascinanți precum Hans Urs von Balthasar (Mysterium Paschale. The Mystery of Easter) sau Jürgen Moltmann (The Crucified God), încercau să depășească înțelegerea tradițională, patristică a conceptului de impasibilitate. Această deconstrucție constituia baza unei teologii formulate într-un limbaj contemporan, care să aibă în centru un Dumnezeu sensibil la suferința lumii, solidar cu aceasta, departe de apatheia atribuită Divinităţii de filozofia şi patristica greacă. N. Steinhardt împărtășea universul de idei cu teologii menționați. O dovadă a acestui univers comun de idei îl constituie, printre altele, paralela dintre procesul lui Socrate și moartea lui Hristos - o temă dragă lui N. Steinhardt ${ }^{30}$, care apare și la Jürgen Moltmann în contextul interpretării strigătului de pe

${ }^{28}$ Citat în eseul „Un caz de recurs la splendoare: Miorița” în Nicolae STEINHARDT, Prin alții spre sine, Iaşi, Edit. Polirom, 2012, p. 175, p. 177-178.

29 Nicolae Steinhardt, Prin alții spre sine, Iași, Edit. Polirom, 2012, p. 176; IDEM, Dăruind vei dobândi, ediția a IV-a, Cluj-Napoca, Edit. Dacia, 2002, p. 56; IDEM, Jurnalul fericirii, p. 372.

${ }^{30}$ Nicolae StEInHARDT, Jurnalul fericirii, p. 57-58; IDEM, Dăruind vei dobândi, p. 93-96. 
Cruce $^{31}$. În plus, opera lui Jürgen Moltmann, The Crucified God, se raportează la Dietrich Bonhoeffer și la Hans Urs von Balthasar, așa cum am observat că procedează și scriitorul român. În ciuda originalității și intuiţiilor sale teologice, N. Steinhardt poate fi considerat un reprezentant autohton al curentului teologic apusean menționat anterior, care oferea impasibilităţii o reinterpretare modernă.

Așadar, sub influența teologiei apusene, lipsa impasibilităţii pe Cruce îi permite lui Steinhardt să afirme totala vulnerabilitate a Mântuitorului, până la deznădejde. Cine i-ar putea reproșa așa ceva unui om care, aflat într-o situaţie-limită, caută compasiunea unui Dumnezeu compătimitor?

Într-un timp de criză socială și umană, precum cea determinată de pandemia pe care o traversează umanitatea în acest moment, gândirea Părintelui N. Steinhardt este mai actuală ca oricând. Imaginea lui Hristos suferitor și compătimitor poate reprezenta, în acest context, antidotul spiritual capabil să combată fenomenul alienării care îl amenință pe om. Este imaginea unui Dumnezeu viu, care vine să-Și ofere sprijinul cu sensibilitatea celui ce a experimentat vulnerabilitatea în propria Sa viață.

$\cos 80$

\section{Bibliografie}

1. CHIFĂR, Nicolae, Istoria creștinismului I, Sibiu, Edit. Universităţii „Lucian Blaga”, 2007.

2. GAVRILYUK, Paul L., Pătimirea Dumnezeului nepătimitor. Dialecticile gândirii patristice, trad. Dragoș Dâscă, Iași, Edit. Doxologia, 2013.

3. HAYOUN, Maurice-Ruben, „Iudaismul”, în Jean DELUMEAU (coord.), Religiile lumii, trad. Carol Litman, București, Edit. Humanitas, 2014.

\footnotetext{
31 Jürgen MoltmanN, op. cit., p. 145-146.
} 
4. Lacoste, Jean-Yves (ed.), Encyclopedia of Christiam Theology, vol. 2, New York, Londra, Edit. Routledge, 2005.

5. Moltmann, Jürgen, The Crucified God: the Cross of Christ as the Foundation and Criticism of Christian Theology, trad. R. A. Wilson și John Bowden, Minneapolis, Edit. Fortress Press, 1993.

6. PINTEA, Ioan, Insoțiri în Turnul Babel, Craiova, Edit. Omniscop, 1996.

7. PITRE, Brant, Fiul lui Dumnezeu? Pledoarie pentru Isus, trad. Tatiana Niculescu, București, Edit. Humanitas, 2017.

8. RATZINGER, Joseph, Isus din Nazaret. Partea a II-a. De la intrarea in Ierusalim la Inviere, trad. Cristian Langa, Cristina Palici și Mihai Pătrașcu, Târgu-Lăpuş, Edit. Galaxia Gutenberg, 2012.

9. STĂNILOAE, Dumitru, Teologia dogmatică ortodoxă, vol. II, ediția a doua, București, Edit. Institutului Biblic şi de Misiune al Bisericii Ortodoxe Române, 1997.

10. SteInHARDT, Nicolae, Dăruind vei dobândi, ediția a IV-a, ClujNapoca, Edit. Dacia, 2002.

11. IDEM, Jurnalul fericirii, Cluj-Napoca, Edit. Dacia, 1995.

12. IDEM, Prin alții spre sine, Iaşi, Edit. Polirom, 2012.

13. TOMOIOAGĂ, Florin Toader, „Despre autoritate și libertate în sistem", în rev. Convergențe (https://convergente.ro/despreautoritate-si-libertate-in-sistem/).

14. Von Balthasar, Hans Urs, Mysterium Paschale. The Mystery of Easter, trad. și introducere Aidan Nichols, San Francisco, Edit. Ignatius Press, 2005. 